\title{
INVESTIGATED THE SUPRAMOLECULAR INTERACTION OF TRAMADOL HYDROCHLORIDE WITH P-SULFONATED CALIX]4,6,8]ARENE
}

\author{
QING-HUA ZHAO, CAI-PING CHEN, TAO-TAO PANG, LI-MING DU*, \\ YAN LI, JIAN-HONG XIE, YUN-LONG FU
}

School of Chemistry and Material Science, Shanxi Normal University, Linfen, Shanxi 041004, P.R. China

\section{ABSTRACT}

In this paper, the interaction behavior of p-sulfonated calix[n]arene ( $\mathrm{SCnA}$ ) with tramadol hydrochloride was investigated by fluorescence spectra, ${ }^{1} \mathrm{H}$ NMR spectra, and theoretical calculations in aqueous solution. At the optimized conditions, the fluorescence intensity of tramadol hydrochloride showed positive correlation to the concentration of SCnA, which led to a validated, simple, and sensitive fluorescence quenching method for the determination of tramadol hydrochloride was established for the first time. Moreover, the interaction based on SCnA superstructure provided has promising potential for therapeutic monitoring and pharmacokinetics and clinical application

Keywords: Tramadol hydrochloride; Spectrofluorometry; Supramolecular interaction; p-sulfonated calyx[n]arene

\section{INTRODUCTION}

Tramadol hydrochloride, $( \pm)$-E-2-[ ( dimethylamino ) methyl ]-1-( 3-methoxy phenyl ) cyclohexanol hydrochloride ( TR, Scheme 1.b) is a centrally acting analgesic structurally related to codeine and morphine, analgesic activity in efficacy and potency that ranges between weak opioids and morphine ${ }^{1-4}$. A number of assays have been reported for detection of TR in biological and pharmaceutical samples, including chromatographic ${ }^{5-11}$, mass spectrometric ${ }^{11-13}$, spectrophotometric $\mathrm{c}^{14-16}$, and Capillary electrophoresis ${ }^{17}$. However, chromatography requires the use of organic solvents, expensive instruments, and time-consuming operating steps ${ }^{5-10}$. The reported method of spectrophotometry was based upon the oxidation reaction between the drug and alkaline potassium permanganate,or was based on the reaction of tramadol hydrochloride with 4-chloro-7-nitrobenzofurazan (NBD-Cl) ${ }^{13}$. Some other methods are showed low conveniency and limited extending potential 14,15. Therefore, simple and sensitive detection method is in urgent need for determination of TR, and no fluorescence analyst method is available for the detection of TR to the best of our knowledge.<smiles>CCCCCCCc1cc(S(=O)(=O)O)cc(C)c1O</smiles>

a

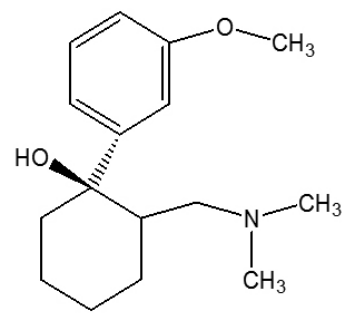

b
Scheme 1 The structure of $p$-sulfonated calyx $[n]$ arene $(n=4,6,8)$ (b) and Tramadol hydrochloride(a)

Supramolecular chemistry provides a possibility for selective detection of TR due to supramolecular interaction. Specially, Calix[n]arenes are constructed from alternating phenol and methylene groups, such as a bowl shape which results in form a hydrophobic and electron rich cavity with excellent recognition ability, which is well-suited to the formation of inclusion complexes and have attracted considerable attentions in the host-guest chemistry ${ }^{18-21}$. The sulfonation of calix $[n]$ arenes (Scheme 1.a )that is a kind of calixarene derivative, due to conquer the poor solubility of calixarenes in aqueous solution, showing favourable bonding properties in aqueous solution are becoming increasingly important in the fields of supramolecular chemistry. Recently, the application of p-sulfonated calix[n]arenes in inorganic ions $s^{22,23}$, organic molecules ${ }^{24}$, chemical dyes ${ }^{25,26}$, biological ${ }^{27-29}$ and medical ${ }^{30,31}$ aspects has occupied the current interest.
In this paper, $\mathrm{p}$-sulfonated calix[n]arene is employed as the host molecule to investigate the inclusion interaction between $\mathrm{SCnX}$ and TR by different way, including fluorescence spectroscopy, thermodynamic parameters, nuclear magnetic resonance (NMR) and Molecular modeling. Investigate the inclusion interaction by fluorescence spectroscopy, then comparative study the effect of temperature and $\mathrm{pH}$ to stability constant of the complex. Thermodynamic property was studied to obtain thermodynamic parameters of the complex, through Molecular modeling and ${ }^{1} \mathrm{H}$ NMR studies were implemented to determine the possible binding mechanism of the interaction. We wish this research will provide the useful information for improving the bioavail ability and detection technology of TR.

\section{EXPERIMENTAL}

\section{Materials and reagents}

TR was obtained from the Chinese National Institute for the Control of Pharmaceutical and Biological Products (Beijing, China) without further treatment. The stock solution of $1.0 \times 10^{-4} \mathrm{M}$ was prepared by directly dissolving in double-distilled water. SC4A, SC6A and SC8A were respectively purchased from Great Britain and Shanghai Chemical Industry Co., Ltd. SCnA $(\mathrm{n}=4,6,8)$ stock solution of $1.0 \times 10^{-4} \mathrm{M}$ was prepared respectively in a 100 $\mathrm{ml}$ volumetric flask. Stock standard solutions were stable for several weeks at room temperature. Standard working solutions were prepared by diluting the stock standard solutions with double-distilled water before use. All other chemicals were of analytical reagent grade, and double-distilled water was used throughout the procedure.

\section{Apparatus}

Fluorescence spectra and intensity measurements were obtained using a Hitachi F-4500 spectrofluorimeter equipped with a150W xenon lamp (Japan). The slit widths of both excitation and emission monochromators were set to $5 \mathrm{~nm}$. The fluorescence spectra were recorded at a scan rate of $1200 \mathrm{~nm} \mathrm{~min}$ '. All measurements were performed in a standard $10 \mathrm{~mm}$ path-length quartz cell set to a temperature of $25.0 \pm 0.5^{\circ} \mathrm{C}$. The $\mathrm{pH}$ values were measured using a pHS-3 TC digital precision pH meter (Shanghai, China). 1H NMR spectra were obtained using a Bruker AV-600 MHz spectrometer (Switzerland) in D2O. Molecular modeling calculations were optimized at the B3LYP/6-31 G (d) level of density functional theory with the Gaussian 03 program.

Spectra measurement procedure

The fluorescence measurements were carried out in the absence or presence of TR solution. $1 \mathrm{ml}$ aliquot of the stock solution of TR was transferred into a $10 \mathrm{ml}$ colorimetric vessel, to which an appropriate amount of $1.0 \times 10^{-4} \mathrm{~mol} / 1$ SCnA was respectively added, followed by $1.0 \mathrm{ml}$ of Britton- Robinson buffer solution ( $\mathrm{pH}$ 7.4). The 1 solution was diluted to final volume with doubledistilled water, stirred thoroughly, and shaken for $15 \mathrm{~min}$ at room temperature. The fluorescence intensity values of the solution (TR-SC4A) and the blank solution (TR) were measured at $220 \mathrm{~nm}$ using an excitation wavelength of $297.03 \mathrm{~nm}$. SC6A, SC8A and TR experimental procedures as above. 


\section{RESULTS AND DISCUSSION}

\section{Spectral characteristics}

Because the same trends showed for three SCnA (i.e., SC4A, SC6A or SC8A), the following research used the SC4A as example. Fluorescent emission of SC4A showed undetectable, nevertheless, TR exhibited very mightily native fluorescence in aqueous solution (Figure1.SC4A, cure1).After the addition of SC4A in TR solution, a dramatic quenching change of fluorescence was observed (Figure 1.SC4A, cure 2-10). This should be attributed to the inclusion of TR by SC4A to change the space structure or conformation of TR and produce the inclusion complexes. Furthermore, with the increasing size of the calixarene ring, $\mathrm{SC} 4 \mathrm{~A}<\mathrm{SC} 6 \mathrm{~A}<\mathrm{SC} 8 \mathrm{~A}$, the order of the fluorescence intensity changes was consistent (Figure1.SC6A, Figure 1.SC8A).
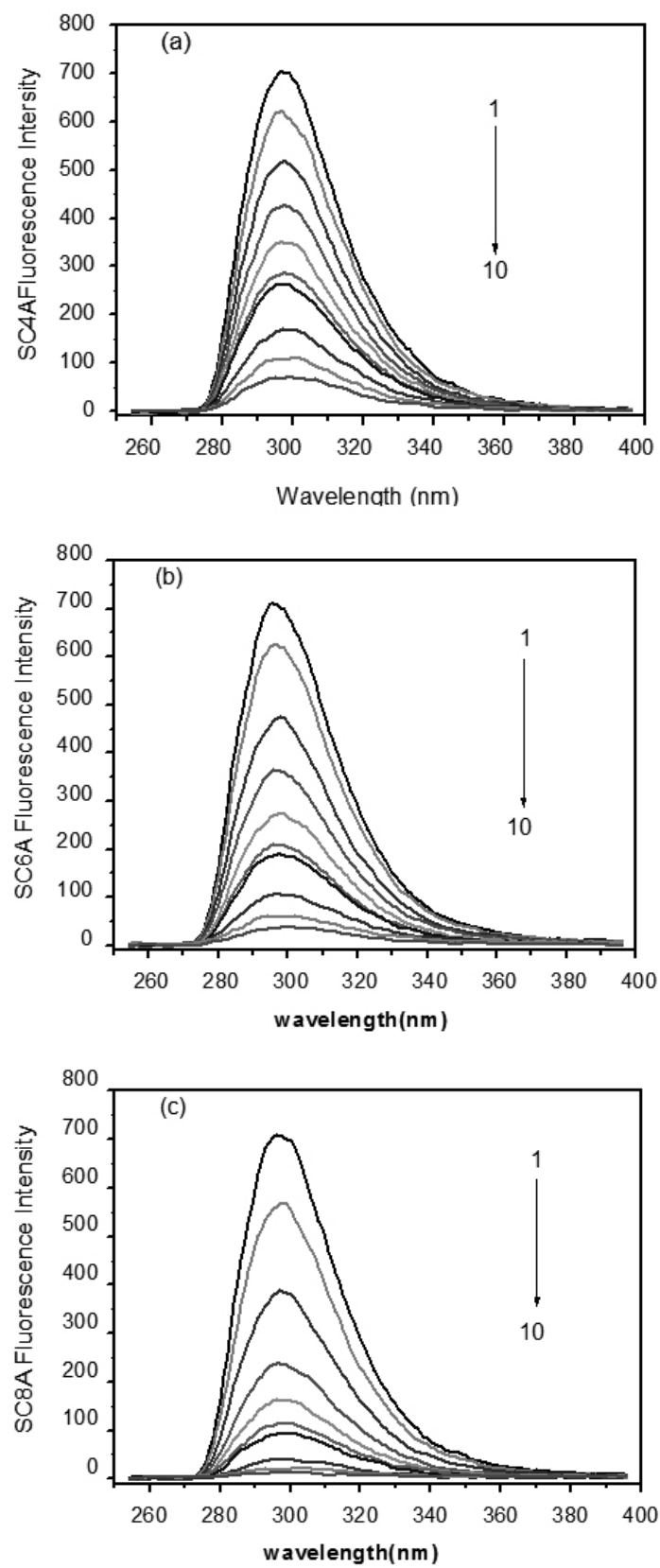

Figure 1. The fluorescence spectra of TR in different concentrations of $\mathrm{SC} n \mathrm{~A}(n=4,6,8)$ in Britton-Robinson buffer solutions. The concentrations of SCnA $\left(10^{-4} \mathrm{~mol} \mathrm{~L}^{-1}\right)$ : (1) 0 ; (2) 0.1 ; (3) 0.3 ; (4) 0.5 ; (5) 0.7 ; (6) 0.9 ; (7) 1.0 ; (8) $1.5 ;$ (9) $2.0 ;$ (10) $2.5 ; \mathrm{C}_{\mathrm{TR}}=1.0 \times 10^{-4} \mathrm{~mol} \mathrm{~L}^{-1}$.
Interaction mechanism the inclusion complex

Although the fluorescent emission of pure TR was very mightily, the fluorescence intensity greatly quenching after they interacted with the hydrophobic cavity of SCnA. The Interaction mechanism of inclusion complex were explained from the following several aspects:

(1). Stoichiometry and association constant of the inclusion complex. Assuming that SCnA and TR forms a 1:1 ratio complex, the following expression can be written as

$$
T R+S C n A \leftrightarrow T R-S C n A(1)
$$

The formation constant of the complex $(\mathrm{K})$ is given by

$$
K=\frac{\mathrm{C}_{\mathrm{TR}-\mathrm{SC} n \mathrm{~A}}}{\mathrm{C}_{\mathrm{TR}} \times \mathrm{C}_{\text {SCnA }}}(2)
$$

An equation of inclusion constant $\mathrm{K}$ of the complex with guest- host was used to calculate the inclusion constant ${ }^{32}$ :

$$
\frac{1}{F-F_{0}}=\frac{1}{\left(F_{¥}-F_{0}\right) K C \mathrm{SCnA}}+\frac{1}{F_{¥}-F_{0}}(3)
$$

Where, $\mathrm{C}_{\mathrm{G}}$ is the original concentration of the TR, $\mathrm{C}_{\mathrm{H}}$ is the original concentration of the $\mathrm{SCnA}, F$ is the fluorescence intensity of TR in the absence of SCnA, $F_{\infty}$ is the fluorescence intensity when all of the TR molecules are essentially complexed with $\mathrm{SCnA}$, and $F$ is the observed fluorescence intensity at each $\mathrm{SC} n \mathrm{~A}$ concentration tested. $K$ is the association constant of the complex.

In the double reciprocal plot was obtained between $1 /\left(\mathrm{F}-\mathrm{F}_{0}\right)$ and $1 / \mathrm{C}$ $\mathrm{SCnA}$ (Figure2), the fluorescence quenching values $1 /\left(\mathrm{F}-\mathrm{F}_{0}\right)$ show good linear relationship with $\mathrm{SCnA}$ concentration $1 / \mathrm{CSCnA}$ for a certain range of concentrations, which supported the formation of a 1:1 complexes (TR and $\mathrm{SCnA}$ ) with a binding constant at $\mathrm{pH} 7.4$ were $6.84 \times 10^{4}, 7.5 \times 10^{4}, 8.72 \times 10^{4} \mathrm{~L}$ $\mathrm{mol}^{-1}$ in presence of SC4A, SC6A and SC8A, respectively. These values were determined by dividing the intercept by the slope of the corresponding lines. It is evident that the complex stability constant monotonically increased with the number of phenol units in the calixarene ring.
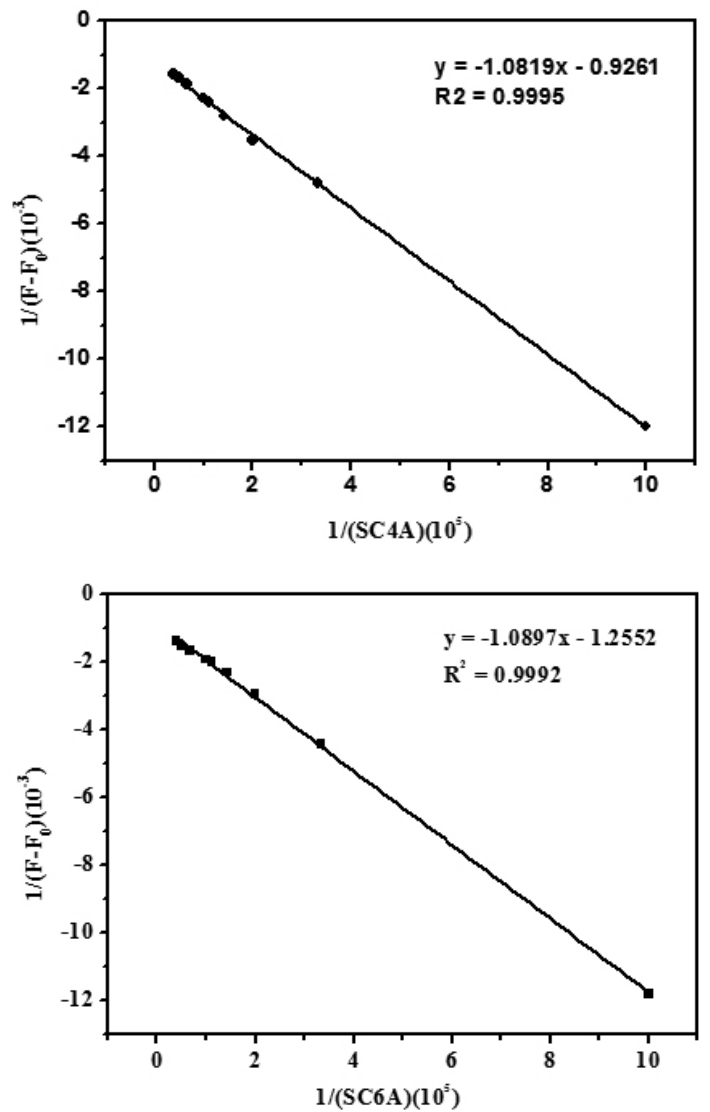


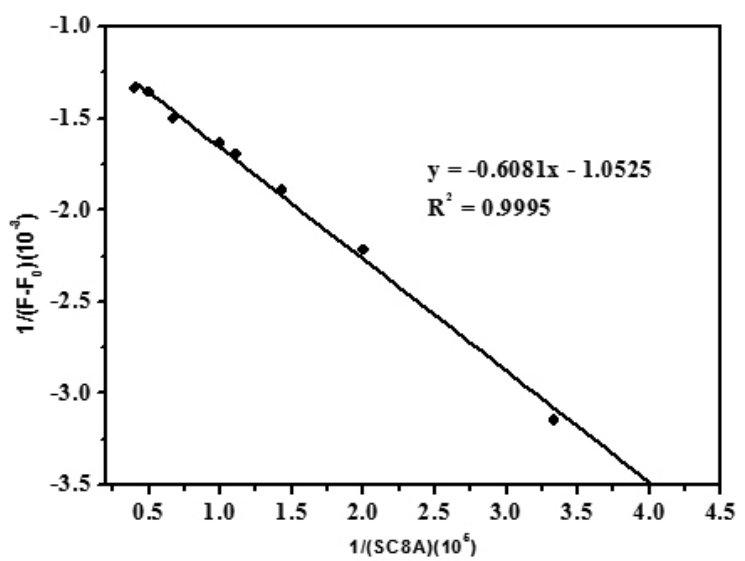

Figure2. Plot of $1 /\left(F-F_{0}\right)$ versus $1 /[S C n A]$ of SCnA-TR complex.

By the Job's plot using to calculate the association ratio, the formation of 1:1 SCnA-TR complex was also confirmed ${ }^{33}$. The solutions of SCnA and TR were mixed in a different mole ratio while keeping the total concentrations of these two components to be a constant. The maximum of the relative fluorescence intensity was observed when $[\mathrm{SCnA}] /([\mathrm{SCnA}]+[\mathrm{TR}])=0.5$.A typical Job's plot for the inclusion complexation of SCnA with TR was shown (Figure 3).

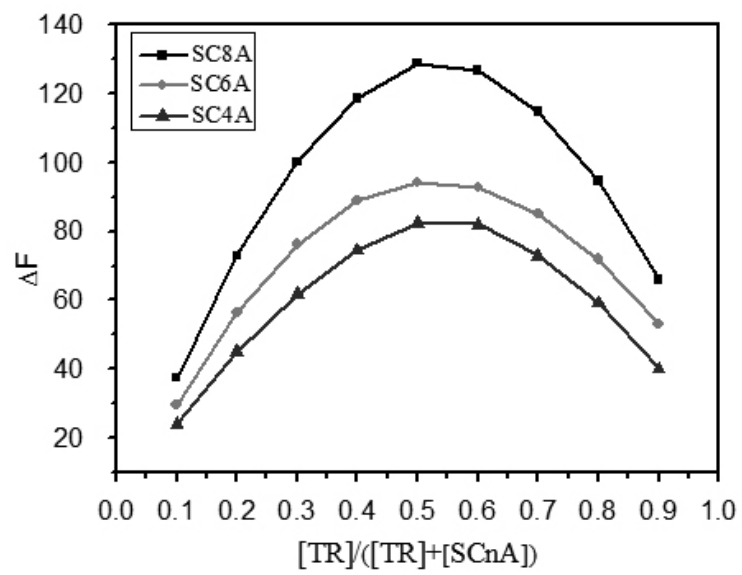

Figure3. Job's plot for the complexation of TR with $\mathrm{SCn} A$ in BrittonRobinson buffer solution $(\mathrm{pH} 6.00)$ at $25 \square$. ([TR $]+[\mathrm{SCnA}])=1.0 \times 10^{-5} \mathrm{~mol}$ $\mathrm{L}^{-1}$ ).

(2). Thermodynamic parameter value of inclusion complexation. The binding constants at various temperatures were investigated, in order to explain the thermodynamic origins of the formation of inclusion complex. At different temperature, the complex stability constants $(\mathrm{K})$ and thermodynamic parameters were obtained form 1:1 intermolecular complexation of TR with SCnA $(n=4,6,8)$,by fluorescence spectra method in Britton-Robinson buffer solution $(\mathrm{pH}=7.4)$ as shown in Table 1 . The relationship of stability constant (K) with temperature T can be described by Van't Hoff equation ${ }^{34}$ shown as follows:

$$
\operatorname{LnK}=-\frac{\Delta \mathrm{H}}{\mathrm{RT}}+\frac{\Delta \mathrm{S}}{\mathrm{R}}(4)
$$

Where R was the gas constant, The enthalpy change $(\Delta \mathrm{H})$ and the entropy change $(\Delta \mathrm{S})$ associated with complex formation. Supposing $\mathrm{H}$ and $\mathrm{S}$ were constant in the range of experiment temperature.

A plot of $\ln K$ versus 1/T was linear within experimental error, which was shown in Figure 4. The value of the changes in enthalpy and entropy could be obtained from the slopes and the intercepts, respectively. The free energy change $(\Delta \mathrm{G})$ was estimated from the following relationship ${ }^{35}$ :

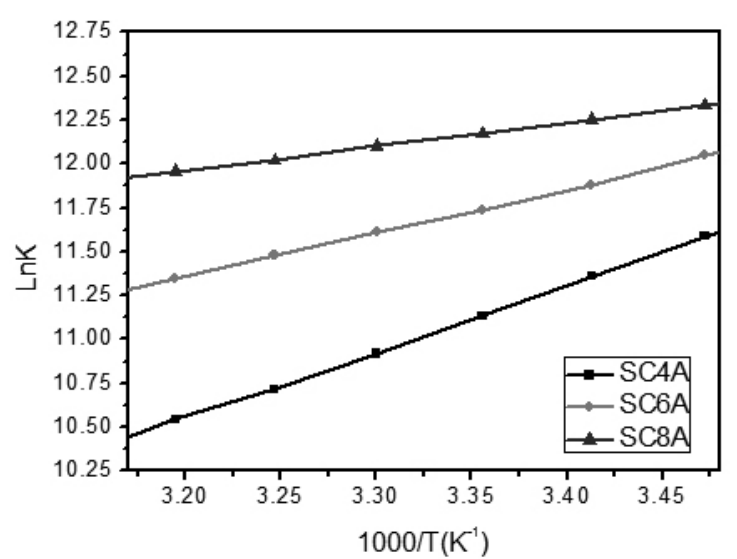

Figure 4. Van't Hoff plot, $\mathrm{pH} 7.4, \mathrm{C}_{\mathrm{TR}}=1.0 \times 10^{-4} \mathrm{~mol} \mathrm{~L}^{-1}$

Table 1. The complexation of TR with SCnA thermodynamic parameters.

\begin{tabular}{|c|c|c|c|c|c|}
\hline & $\mathrm{T}(\mathrm{K})$ & $\begin{array}{c}K(\mathrm{~L} \\
\left.\mathrm{mol}^{-1}\right)\end{array}$ & $\begin{array}{l}\Delta \mathrm{H}(\mathrm{kJ} \\
\left.\mathrm{mol}^{-1}\right)\end{array}$ & $\begin{array}{l}\Delta \mathrm{G}(\mathrm{kJ} \\
\left.\mathrm{mol}^{-1}\right)\end{array}$ & $\begin{array}{c}\Delta \mathrm{S}(\mathrm{J} /(\mathrm{mol} \\
\left.\mathrm{K})^{-1}\right)\end{array}$ \\
\hline \multirow{6}{*}{ SC4A } & 288 & $1.08 \times 10^{5}$ & \multirow{6}{*}{-31.62} & -27.731 & \multirow{6}{*}{-13.51} \\
\hline & 293 & $8.56 \times 10^{4}$ & & -27.66 & \\
\hline & 298 & $6.84 \times 10^{4}$ & & -27.6 & \\
\hline & 303 & $5.51 \times 10^{4}$ & & -27.53 & \\
\hline & 308 & $4.50 \times 10^{4}$ & & -27.46 & \\
\hline & 313 & $3.79 \times 10^{4}$ & & -27.4 & \\
\hline \multirow{6}{*}{ SC6A } & 288 & $1.71 \times 10^{5}$ & \multirow{6}{*}{-20.63} & 28.82 & \multirow{6}{*}{28.42} \\
\hline & 293 & $1.44 \times 10^{5}$ & & -28.96 & \\
\hline & 298 & $1.25 \times 10^{5}$ & & -29.1 & \\
\hline & 303 & $1.11 \times 10^{5}$ & & -29.25 & \\
\hline & 308 & $0.97 \times 10^{5}$ & & -29.39 & \\
\hline & 313 & $0.85 \times 10^{5}$ & & -29.53 & \\
\hline \multirow{6}{*}{ SC8A } & 288 & $2.48 \times 10^{5}$ & \multirow{6}{*}{-11.44} & -29.54 & \multirow{6}{*}{62.86} \\
\hline & 293 & $2.28 \times 10^{5}$ & & -29.85 & \\
\hline & 298 & $2.10 \times 10^{5}$ & & -30.17 & \\
\hline & 303 & $1.94 \times 10^{5}$ & & -30.48 & \\
\hline & 308 & $1.80 \times 10^{5}$ & & -30.8 & \\
\hline & 313 & $1.66 \times 10^{5}$ & & -31.11 & \\
\hline
\end{tabular}

The complexation thermodynamic parameters shown in Table 1 indicated that the negative sign for the enthalpy change and free energy meant that the interaction process was exothermal and spontaneous, but with accompanying a small entropic loss, it also indicated that higher temperature was unfavorable to the formation of inclusion complexes. Hydrogen bonding, $\mathrm{p}-\mathrm{p}$ interaction, electrostatic interaction, hydrophobic interaction, dipole-dipole or Van der Waals would contribute to the favorable enthalpy change. Therefore, the present experiment should be conducted under a lower temperature,at room temperature. The complexation thermodynamic parameters indicated that the complexation of $\operatorname{SCnA}(n=4,6,8)$ with TR was mainly driven by the enthalpy change which mainly to the electrostatic interaction,which suggested that the electrostatic interaction and structural matching effect were the dominant hostguest complex stabilizing factor.

(3). Influence of reaction time

The effect of reaction time was studied. As shown in Figure 5, the fluorescence intensity reached a maximum within $20 \mathrm{~min}$ after the reagents had been added, and remained constant for at least $5 \mathrm{~h}$. Hence, the reaction was carried out for $20 \mathrm{~min}$, room temperature for $20 \mathrm{~min}$ was selected as a standard reaction condition. 


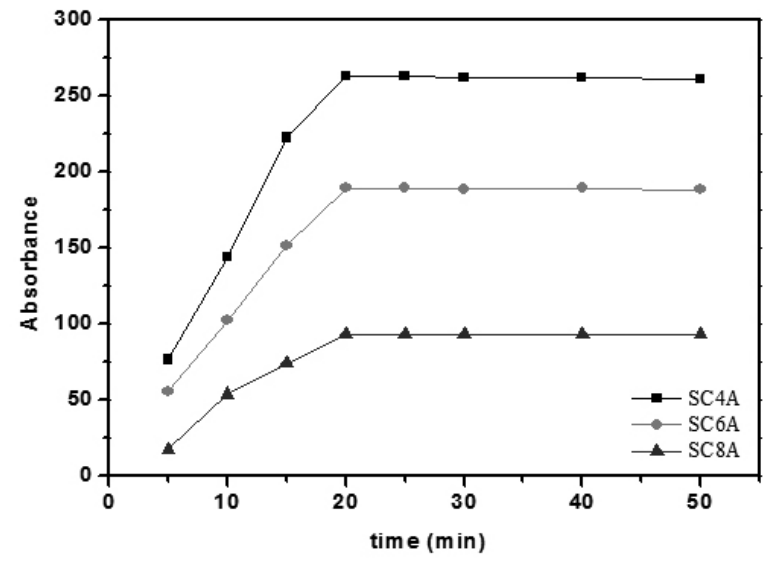

Figure 5. Influence of reaction time on the fluorescence intensity, $\mathrm{pH}$ $7.4,(\mathrm{TR})=1.0 \times 10^{-4} \mathrm{~mol} \mathrm{~L}^{-1}$
(4).Influence of $\mathrm{pH}$. The complexation of TR with $\mathrm{SCnA}$ was also studied in acidic, neutral and basic media. The $\mathrm{pH}$ dependence of association constants of was carried out the $\mathrm{pH}$ range of 4.0-11.0, which suggest that large affinity of $\mathrm{TR}$ to $\mathrm{SCnA}$ in the fluorescence spectra was found irrespective of $\mathrm{pH}$. As seen in Table 2.The binding constants were a little sensitive to $\mathrm{pH}$ with increasing the size of SCnA cavity, which imply that the dominant host-guest complex stabilizing factor was not Coulomb force but the electrostatic interaction and structural matching effect . Only take into consideration the optimal inclusion condition of SCnA (6.0-8.5) and physiological environment of drug action, the buffer of $\mathrm{pH} 7.4$ was chosen in the following study.

From the Supporting information, with increasing the $\mathrm{pH}$ from $\mathrm{pH} 7.4$ to 9.0 or more basic condition the electrostatic interaction between TR and $\mathrm{SCnA}$ is becoming much more weaker, it meant that the binding constant of $\mathrm{pH} 7.4$ is larger than other $\mathrm{pH}$. With increasing the $\mathrm{pH}$, deprotonation of the phenolic $\mathrm{OH}$ groups of $\mathrm{SCnA}$ could be further strengthened which lead to the hydrogen bonds strengthened among the phenolic hydroxyl groups allowing conformation flexibility for the calixarene ring. So, in experimental condition $\mathrm{pH} 7.4$, the electrostatic interaction of TR and the negatively charged sulphonyl groups of $\mathrm{SCnA}$ is existed and the association constant is the maximum.

Table 2. Complex association constants for 1:1 intermolecular complexation of TR with SCnA in different $\mathrm{pH}$.

\begin{tabular}{|c|c|c|c|c|c|c|c|c|}
\hline \multicolumn{2}{|c|}{} & \multicolumn{7}{|c|}{$\mathrm{pH}$} \\
\hline & 2 & 4 & 5 & 6 & 7.4 & 9 & 11 \\
\hline \multicolumn{2}{|c|}{} & $n=1: 1$ & $\mathrm{n}=1: 1$ & $\mathrm{n}=1: 1$ & $\mathrm{n}=1: 1$ & $\mathrm{n}=1: 1$ & $\mathrm{n}=1: 1$ & $\mathrm{n}=1: 1$ \\
\hline $\mathrm{SC} 4 \mathrm{~A}$ & $\mathrm{~K}$ & $2.97 \times 10^{4}$ & $6.23 \times 10^{4}$ & $2.47 \times 10^{4}$ & $8.4 \times 10^{4}$ & $1.08 \times 10^{5}$ & $6.74 \times 10^{4}$ & $1.63 \times 10^{4}$ \\
\hline & $\mathrm{R}^{2}$ & 0.9962 & 0.9987 & 0.9954 & 0.9989 & 0.9986 & 0.9962 & 0.9975 \\
\hline $\mathrm{SC6A}$ & $\mathrm{K}$ & $1.15 \times 10^{4}$ & $8.61 \times 10^{4}$ & $7.38 \times 10^{4}$ & $2.38 \times 10^{5}$ & $1.71 \times 10^{5}$ & $1.62 \times 10^{4}$ & $1.87 \times 10^{3}$ \\
\hline & $\mathrm{R}^{2}$ & 0.9985 & 0.9992 & 0.9972 & 0.9991 & 0.9965 & 0.9988 & 0.9876 \\
\hline $\mathrm{SC} 8 \mathrm{~A}$ & $\mathrm{~K}$ & $1.43 \times 10^{5}$ & $2.07 \times 10^{5}$ & $2.44 \times 10^{5}$ & $2.36 \times 10^{5}$ & $2.48 \times 10^{5}$ & $2.05 \times 10^{5}$ & $1.18 \times 10^{4}$ \\
\hline & $\mathrm{R}^{2}$ & 0.9983 & 0.9993 & 0.9997 & 0.9995 & 0.9988 & 0.9995 & 0.999 \\
\hline
\end{tabular}

(5). ${ }^{1} \mathrm{H}$ NMR study. The formation of TR-SCnA inclusion complex could be confirmed by $1 \mathrm{H}$ NMR spectroscopy in $\mathrm{D}_{2} \mathrm{O}$ at room temperature. (Figure 6). Compared with the proton resonance of the unbound TR molecule(Figure 6B), the resonance of protons $\mathrm{H} 3, \mathrm{H} 4, \mathrm{H} 5$, and $\mathrm{H} 6$ of the bound TR in the $1 \mathrm{H}$ NMR spectrum of TR-SC4A complex experienced a progressively up-field shift (Figure 6C), indicating that SC4A binds selectively to the cyclohexanol group residues due to cooperative hydrophobic and ion-dipole interactions, but because of the excellent matched size and morphology, cyclohexanol group residues was enclosed in the cavity of SC4A more tightly and was shown obviously. The chemical shift of the methoxy protons is practically unchanged, indicating this part of the molecule was located just outside the SC4A host. All the $\mathrm{H}$ signals of $\mathrm{N}$-methylene protons and $\mathrm{N}$-methyl significantly shifted upfield.This feature shows that TR part of the molecule with the p-sulfonated calix[n]arenes along with a negatively charged sulfonate and electron interactions on the benzene ring.

Figure $7(\mathrm{~A} \rightarrow \mathrm{D})$ shows the $1 \mathrm{H}$ NMR spectra of the formation of a SC6ATR complex and a SC8A-TR complex. Compared with the proton resonances of the unbound TR molecules (Figure 7B), all the $\mathrm{H}$ signals of the bound TR significantly shifted upfield,and with the increase of the number of phenolic units of the calixarene ring, the interaction more strongly and the molecular distance more close.

(6). Molecular modeling calculations were optimized at the B3LYP/6$31 \mathrm{G}(\mathrm{d})^{36}$ level of density functional theory ${ }^{37,38}$ using the Gaussian 03 program. The results confirmed the partial inclusion of TR in the hydrophobic cavity of SC4A(Figure 8). From molecular simulation, it can be seen that cyclohexanol group of the molecule located inside the SC4A host, however, the heterocyclic nitrogen interacted with the negatively charged sulphonyl groups in the SC4A vicinity .

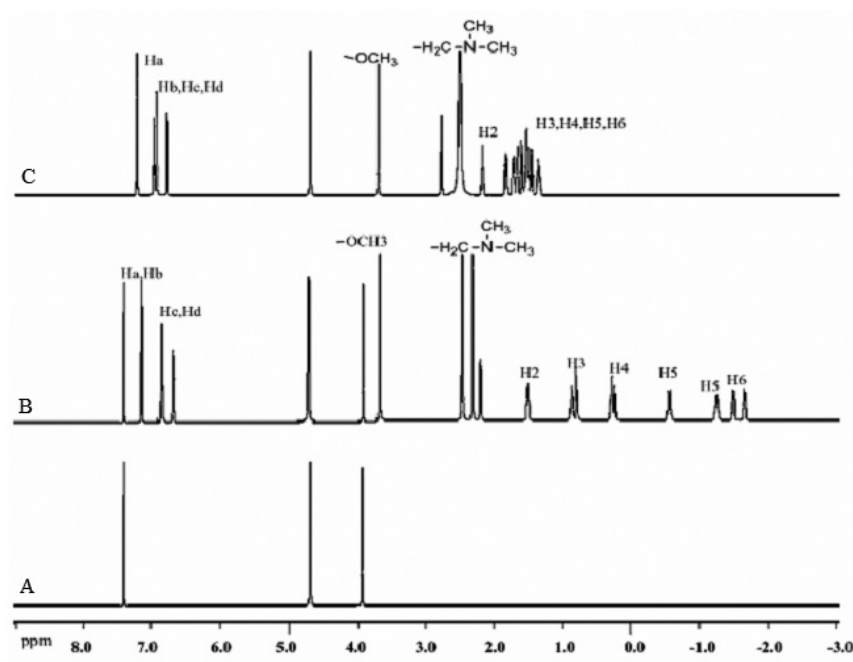

Figure 6. ${ }^{1} \mathrm{H}$ NMR $(600 \mathrm{MHz})$ spectra of SCnA (A) , SC4A-TR (B)and $\mathrm{TR}(\mathrm{C})$ in $\mathrm{D}_{2} \mathrm{O}$. 

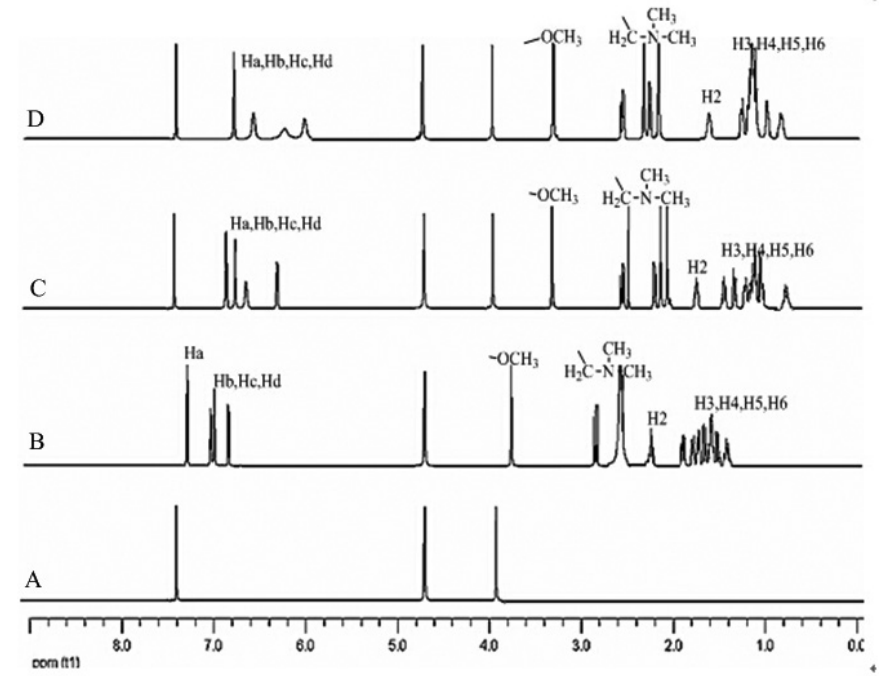

Figure 7. ${ }^{1} \mathrm{H}$ NMR (600 MHz) spectra of SCnA (A),TR (B), SC6A-TR (C)and SC8A-TR (D) in $\mathrm{D}_{2} \mathrm{O}$.

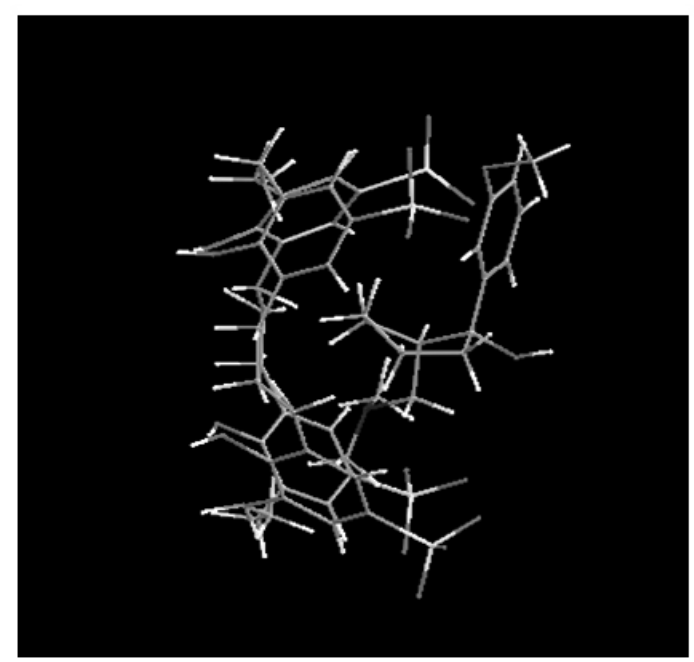

Figure 8. Energy-minimized structure ofTR- SC4A complex in the ground state using sticks for rendering the atoms. Color codes for TR and SC4A: oxygen, red; nitrogen, blue; carbon, dark gray; hydrogen, gray.

\section{CONCLUSIONS}

In this work, the supramolecular interaction of $\mathrm{TR}$ with p-sulfonated calix $[4,6,8]$ arene were investigated for the first time, and characterized via fluorescence spectroscopy and 1H NMR, moreover the stability constants, binding ratio, enthalpy and entropy of complexation were studied and analyzed respectively. The inclusion stoichiometric ratio of 1:1 was verified, and the inclusion constant was estimated. Density functional theory calculations were carried out to propose the possible molecular inclusion model of TR with SC4A. These research results were consistent with the fluorescence discussion and 1HNMR results. The complex between TR and SCnA may be used as a fluorescence probe and a fluorescence sensor for the detection of nonfluorescent or weakly fluorescent substances, this studies are in progress in our laboratory.

\section{ACKNOWLEDGEMENTS}

This work was supported by the National Natural Science Foundation of China (No. 21171110) and the Research Fund for the Doctoral Program of Higher Education of China (No.20091404110001). Helpful suggestions by anonymous referees are also gratefully acknowledged.

\section{REFERENCES}

1.- R.A. Ghany, M. Nabil, M. Abdel-Aal, W. Barakat, European Journal of Pharmacology 758, 11, (2015)

2.- $\quad$ A. M. Sousa, H. A. Ashmawi, Rev Bras Anestesiol. 65, 186, (2015)

3.- M.. Vazzana, T. Andreani, J. Fangueiro, C. Faggio, C. Silva, A. Santini, M.L. Garcia, A.M. Silva, E.B. Souto, Biomedicine \& Pharmacotherapy, 70, 234, (2015)

4.- $\quad$ R. Smyj, X. P. Wang, F. X.. Han, Profiles of Drug Substances 38, 463, (2013)

5.- Y. C. Gu, J. P. Fawcett, J. Chromatogr. B. 821, 240, (2005)

6.- A. Medvedovici, F. Albu, A. Farca, A. Farca, V. David, J. Pharm. Biomed. Anal. 34, 67, (2004)

7.- M. Zěcevi ć, Ž. Stanković, L. Živanović, B. Jocić, J. Chromatogr. A. 1119, 251, (2006)

8.-M. R. Rouini, Y. H. Ardakani, F. Soltani, H. Y. Aboul-Enein, A. Foroumadi, J. Chromatogr. B. 830,207,(2006)

9.- W. F. Kartinasari, T. Palupi, G. Indrayanto, J. Lio. Chromatogr. R. T. 27 737, (2004)

10.- M. Nobilis, J. Kopecký, J. Květina, J. Chládek, Z. Svoboda, V. Vořŕšek F. Perlík, M. Pour, J. Kuneš, J. Chromatogr. A. 949, 11, (2002)

11.- L.Vlase, S. E. Leucuta, S. Imre, Talanta 75, 1104, (2008)

12.- B. N. Patel, N. Sharma, M. Sanyal, P. S. Shrivastav, J. Pharm. Biomed Anal. 49, 354, (2009)

13.- L. Chytil, O. Matoušková, O. Černá, P. Pokorná, V. Vobrubac, F. Perlík, O. Slanař, J. Chromatogr. B. 878, 481, (2010)

14.- H. E. Abdellatef, J. Pharm. Biomed. Anal. 29, 835, (2002)

15.- A. Küçük, Y. Kadıŏlu, IL Farmaco 60, 163, (2005)

16.- H. E. Abdellatef, M. M. El-Henawee, H. M. El-Sayed, M. M. Ayad, Spectrochim. Acta A.. 65, 1087, (2006)

17.- U. B. Soetebeer, M. O. Schierenberg, H. Schulz, G. Grünefeld, P. Andresen, G. Blaschke, J. Chromatogr. B. 745, 271, (2000)

18.- 18 A. Rouis, J. Davenas, I. Bonnamour, H. B. Ouada, Physica B, 474, 70, (2015)

19.- R. Galindo-Murillo, A. Olmedo-Romero, E. Cruz-Flores, P. M. Petrar, S. Kunsagi-Mate, J. Barroso-Flores, Computational and Theoretical Chemistry, 1035, 84, (2014)

20.- G. Zheng, M. Chen, X. Y. Liu, J. Zhou, J. Xie, G. W. Diao, Electrochimica Acta, 136, 301, (2014)

21.- Z. Garaiová, M. A. Mohsin, V. Vargová, F. G. Banica, T. Hianik, Bioelectrochemistry 87, 220, (2012)

22.- I. C. Popescu (Hostuc), F. Petru, I. Humelnicu, M. Mateescu, E. Militaru, D. Humelnicu, Journal of Nuclear Materials, 453, 75, (2014)

23.- M. N. Akieh, S. F. Ralph, J. Bobacka, A. Ivaska, Journal of Membrane Science, 354, 162, (2010)

24.- S. A. Fernandes, R. Natalino, P. A. R. Gazolla, M. J. D. Silva, G. N. Jham, Tetrahedron Letters, 53, 1630, (2012)

25.- M. Chen, G. M. Diao, J. Solution. Chem. 40, 481, (2011)

26.- W. Tao, M. Barra, J. Org. Chem. 66, 2158, (2001)

27.- J. L. Atwood, T. Ness, P. J. Nichols, C. L. Raston, Cryst. Growth Des. 2 , 171, (2002)

28.- L. Mutihac, H.J. Buschmann, R.C. Mutihac, E. Schollmeyer, J. Incl. Phenom. Macro. 51, 1, (2005)

29.- V. Safarnavadeh, K. Zare, A. R. Fakhari, Biosensors and Bioelectronics, 49, 159, (2013)

30.- H. Li, J. P. Song, J. B. Chao, S. M. Shuang, C. Dong, Spectrochim. Acta A.. 97, 155, (2012)

31.- Y. Y. Zhou, Q. Lu, C. Liu, S. She, L. Wang, Spectrochim. Acta A.. 64 748, (2006)

32.- C. F. Li, L. M. Du, H. M. Zhang, Spectrochim. Acta A.. 75, 912, (2010)

33.- Y. J. Hua, Y. Liu, X. S. Shen, X. Y. Fang, S. S. Qu, J. Mol. Strucl. 738, $143,(2005)$

34.- W. Tao, M. Barra, J. Chem. Soc., Perkin Trans. 2, 1957, (1998)

35.- M. Megyesi, L. Biczók, Chemical Physics Letters, 424, 71, (2006)

36.- C. Lee, W. Yang, R. G. Parr, Parr. Phys. Rev. B. 37, 785, (1988)

37.- A. D. Becke. J. Chem. Phys. 88, 2547, (1988)

38.- A. D. Becke. Phys. Rev. A. 38, 3098, (1988) 